\title{
La policía en la primera línea contra la pandemia: reflexiones sobre un papel distorsionado
}

\section{The police in the front line against the pandemic: reflections about a blurred role.}

Recibido: 01-06-2021

Aceptado: 28-07-2021

\section{Resumen}

La pandemia causa por el virus COVID-19 ha provocado una crisis sanitaria mundial sin precedentes en las últimas décadas. La reacción mayoritaria de los estados, aparte de las medidas estrictamente sanitarias, ha sido la limitación de los derechos que implicaban movilidad y contacto social a fin de evitar la transmisión de la enfermedad. Prácticamente todos los países han establecido confinamientos de la población de diversa intensidad. Estas medidas han afectado diversamente a los diversos sectores sociales y han tenido una influencia notoria, aunque desigual, en la evolución de la criminalidad, Para el cumplimiento de estas medidas se ha requerido la actuación de la Policía (en menor medida

\section{Cómo citar}

Guillen Lasierra, F. La policía en la primera línea contra la pandemia: reflexiones sobre un papel distorsionado. Revista Constructos Criminológicos. Recuperado a partir de https://constructoscriminologicos.uanl.mx/ index.php/cc/article/view/5

*https://orcid.org/0000-0001-5599-4821

Universidad Autónoma de Barcelona, España al Ejército), Este trabajo pretende demostrar que el papel de la Policía en cada país no ha estado directamente relacionado con la gravedad de la pandemia o la mayor disciplina o indisciplina de la ciudadanía sino en función de la cultura política y los modelos policiales adoptados en los diversos países. Finalmente, el trabajo esboza las pautas que deberían presidir la actuación policial en situación de pandemia para conseguir unas conductas más seguras por parte de la población, sin agravar la situación de los grupos especialmente vulnerables, ni incrementar las desigualdades y mantener la confianza de amplios sectores sociales.

Palabras clave: Policía, Pandemia, Restricciones De Derechos

\section{Abstract}

The pandemic caused by the COVID-19 virus has implied an unprecedented global health crisis in recent decades. Most states' reactions, apart from strictly sanitary measures, have included the limitation of the rights that are connected to mobility and social contact in order to avoid the transmission of the disease. Practically all countries have established population lockdowns of varying intensity. These measures have affected various 
social sectors in different ways and have had a notorious, albeit unequal, influence on the evolution of crime. The enforcement of these measures requires the action of the Police (to a lesser extent the Army). This study aims at showing that the role of the Police in each country has not been directly related to the severity of the pandemic or the greater discipline or indiscipline of the citizens, but rather to the political culture and police models adopted in the various countries. Finally, this work outlines the guidelines that should govern police action in a pandemic situation to achieve safer behavior by the population, without aggravating the situation of especially vulnerable groups, or increasing inequalities and maintaining the trust of broad social sectors.

Key words: Police, Pandemic, Rights' Restrictions

\section{LOS ESTADOS ANTE LA COVID19: NECE- SIDAD DE ACTUAR Y DESCONOCIMIENTO DE LA RESPUESTA ADECUADA}

Todos los estados del mundo se han encontrado con la pandemia sin haber previsto mecanismos para hacerle frente. Si añadimos que la pandemia se extendió a una gran velocidad (en un par de meses estaba prácticamente en todo el mundo), sumió a los Estados en una sensación de impotencia y desbordamiento que, sin duda generaba inseguridad y desesperación entre la población. No había datos sobre las causas o entornos que facilitaban la transmisión, no se conocían todavía todos los síntomas que se le podían asociar, ni, por supuesto, los tratamientos efectivos para combatir las complicaciones de salud que generaba en los infectados. La vacuna tardaría todavía en llegar (hasta entonces el período mínimo de desarrollo de una vacuna era de cuatro años).
El Estado tiene como finalidad última (siguiendo los parámetros hobbesianos) la garantía de la seguridad de sus ciudadanos. El aumento continuo de contagios, ingresos en los hospitales (y en las unidades de cuidados intensivos), así como la cantidad de personas fallecidas que provocaban colas, con varios días de espera en las funerarias, ponía en evidencia la ineficacia del Estado en su supuesta función primordial, circunstancia que provocaba un pánico considerable entre la población (Sheptycki,J. 2020). Los estados sintieron que había que realizar alguna acción visible y drástica que demostrara sus desvelos por la población y extendiera una cierta tranquilidad entre ésta. Una de las características de la nueva enfermedad era su gran capacidad de transmisión, su potencialidad de contagio. Los estados confinaron a la población, de manera que los espacios de sociabilidad (las vías públicas incluidas) se vaciaran de personas potencialmente contagiadoras o contagiables. Se volvió a los confinamientos ya utilizados durante las pandemias desde la Edad Media. La opinión científica dominante avaló totalmente esta medida como adecuada y necesaria.

El desarrollo normativo tanto del confinamiento como de las fases intermedias requería, por una lado, una misión imposible: regular de manera adecuada toda la casuística que se podía producir, porque no era posible prever todas las situaciones que podían darse; y, por otro lado, hacía falta alguna agencia que controlara su cumplimiento por parte de la ciudadanía, denunciando y, si era el caso, poniendo en marcha el procedimiento sancionador, para castigar a los infractores efectivos y disuadir a los hipotéticos futuros. Aquí es dónde los 
estados volvieron a sus orígenes, utilizando el poder más nuclear del estado, el poder de coacción, para garantizar el cumplimiento de la normativa anti-pandemia a través de la policía, que constituye una de las expresiones más concretas del poder del Estado (Sheptycki, J. 2020). Esto despertó, sin duda, cierto entusiasmo entre aquellos que creen que la policía está fundamentalmente para eso, para hacer efectiva la coacción estatal a fin de hacer cumplir la ley. El problema radicaba en qué la decisión de poner a la policía al frente de la lucha anti-Covid19 encubría ciertas trampas y algunos riesgos para la policía y su relación con la ciudadanía (por no mencionar que la situación constituía un factor más que añadir su burnout tradicional, muy marcado, por ejemplo, en el norte de México -Valdivia,J.A., Hernández, G.D., y Maiz,, S.I., 2021-).

\section{LA PANDEMIA ES PRINCIPALMENTE UNA CRISIS SANITARIA}

En primer lugar, hay que afirmar con extrema rotundidad que la pandemia es una crisis que pone en peligro la vida de las personas a través de la difusión de un virus, en este caso, el Covid19. En consecuencia, aquellas personas que pueden hacerle frente de manera más eficiente y eficaz son aquellos que se dedican a la medicina, en sus diferentes especialidades, los sanitarios, los que producen y suministran fármacos, etc. Sin una mejora en el conocimiento del comportamiento del virus, de las causas de transmisión, de sus efectos colaterales en el cuerpo de los afectados, sin mecanismos de prevención de la enfermedad o de una vacuna que inmunice a la población, no es posible controlar ni reducir la pandemia sin un altísimo peaje en vidas humanas que dejaría nuestras sociedades devastadas. Por mucho que otros actores (públicos y privados) se esfuercen, sólo una actuación eficaz de las autoridades y del sector de la salud pueden realmente revertir la expansión de la pandemia.

Existen otros actores que pueden llevar a cabo contribuciones necesarias en tiempos de pandemia: los proveedores de recursos esenciales, los que facilitan el transporte de las personas enfermas o de productos e instrumental médico a centros sanitarios y farmacias, los que ayudan a mantener la higiene pública, vital en estos casos, los que prestan apoyo social a los grupos más vulnerables (especialmente afectados por cualquier crisis), etc. La lista sería, sin duda, interminable. No es discutible que entre aquellos que prestan un servicio muy necesario están aquellos que se dedican a mantener el orden y la seguridad en nuestras ciudades y pueblos. Su contribución es, sin duda, de gran valor. A reflexionar sobre su contenido nos dedicaremos más adelante en este artículo. Ahora simplemente lo que es importante certificar y retener es que una pandemia es una crisis sanitaria, no lo es de delincuencia ni de seguridad (aunque tiene derivaciones en ella que veremos).

\section{LA LIMITACIÓN DE LIBERTADES COMO RESPUESTA VISIBLE SIN RESULTADOS INCONTESTABLES}

Las medidas adoptadas para combatir la pandemia implicaron en algunos casos la derogación temporal explícita de derechos fundamentales básicos (especialmente los relacionados con la libre circulación 
de personas, derecho de reunión y de manifestación). Se ha dicho ya que la restricción prácticamente total de la movilidad había contado con el visto bueno de la mayoría de la comunidad científica. Esta circunstancia hace pensar que hay bases objetivas para escoger las medidas que más pueden contribuir a evitar la difusión de la enfermedad. Para confirmar esto es interesante analizar el tipo de medidas adoptadas (especialmente durante los primeros meses de pandemia) y ver como se relacionó su adopción y puesta en práctica con la incidencia del virus.

En Europa la mayoría de los estados acordó lo que pudiera parecer un confinamiento domiciliario bastante estricto. Existieron, sin embargo, excepciones. La más clara la de Suecia, que no estableció prohibiciones más allá de las reuniones de más de cincuenta personas o el cierre de las universidades. La mayoría de los mensajes de los poderes públicos de aquel país se limitaban a establecer recomendaciones, como no acudir a bares ni lugares de reunión o teletrabajar siempre que fuera posible. Sin duda, hubo ciudadanos que siguieron el consejo, pero los que no lo hicieron no fueron objeto de denuncia ni sanción alguna. Es importante destacar que los motivos de la estrategia suave de las autoridades suecas no tenían como base (como se ha intentado convencer en el resto de Europa) una razón médica o epidemiológica, sino política: no deseaban establecer restricciones de derechos a la ciudadanía de un nivel tan alto, por una cuestión de principios. Se trataba claramente de una decisión política. Un caso parecido, aunque mucho menos radical, lo encontramos en los Países Bajos, donde existieron restricciones, pero de mucha menor intensidad hasta que se adoptó la declaración del estado de alarma en enero de 2021, hecho, este último, que comportó un gran número de protestas considerablemente violentas (no tenían toque de queda nocturno desde la Segunda Guerra Mundial).

El resto de países de la Unión Europea tendieron al confinamiento con diversos niveles: Francia, Alemania o Bélgica siempre permitieron salir a hacer deporte o a pasear y los miembros de la célula de convivencia podían hacerlo juntos, en cambio en España e Italia estaba prohibida cualquier salida del domicilio excepto por causas justificadas (adquirir alimentos o artículos de primera necesidad, ir al médico o a la farmacia o trabajar en servicios esenciales) $y$, en todo caso, las personas tenían que abandonar el domicilio de manera individual, ni tan sólo podían hacerlo en compañía de aquellas personas integrantes de su unidad de convivencia.

Fuera de Europa encontramos un hecho muy significativo en el caso de los Estados Unidos de América. La mayoría de los estados (era una competencia de los gobernadores) acabaron adoptando algún tipo de restricciones, que en algunos casos llegó a constituir confinamiento. En la mayoría de los estados se consideraron los establecimientos que vendían todo tipo de armas como de primera necesidad y continuaron abiertos durante las diversas oleadas del virus. Ciertamente los consumidores corroboraron esta decisión ya que la venta de armas, especialmente de armas de fuego, se incrementó de manera notable durante los primeros meses 
de la pandemia ${ }^{1}$. Es decir, (hay que repetirlo porque puede parecer inverosímil) incluso en los estados en qué hubo confinamiento estricto, los establecimientos que vendían armas pudieron permanecer abiertos al público en la mayoría de los casos por considerarse productos de primera necesidad, como, por ejemplo, los establecimientos de productos de alimentación o las farmacias. También hay que señalar que el presidente federal en aquel momento, Donald Trump, flirteó en diversos momentos con algunas variantes del negacionismo, que rehúsa aceptar la existencia de una pandemia y/o las medidas necesarias para su control. Este escenario, unido al histórico apasionamiento sobre el alcance de la enmienda segunda de la Constitución que, supuestamente, protege la adquisición y posesión de armas como un derecho fundamental facilitaron la adopción de estas medidas protectoras de la venta de armas.

Es muy interesante comprobar como la dureza de las medidas que acabamos de exponer (salvando el caricaturesco caso de los negocios de venta de armas en los Estados Unidos de América) no se corresponden con una afectación inferior del virus ni con un número más bajo de víctimas mortales (Greene; A., 2020; Roché, S., 2020). Por ejemplo, Suecia, casi sin medidas restrictivas de los movimientos de los ciudadanos ha tenido hasta ahora, ciertamente, más víctimas por millón de habitantes que sus vecinos escandinavos (1376 muertos por millón de habitantes ${ }^{2}$ ), pero menos

$1 \quad$ Vid. https://www.thetrace.org/2020/04/the-coronavirus-has-gun-sales-soaring-his-fear-is-selling-to-the-wrongperson/

2 que otros países europeos con medidas mucho más draconianas (Italia -1979 por millón- o España -1662 por millón- ${ }^{3}$ ). Por otra parte, en países con medidas similares (Portugal y España) el nivel de víctimas en la primera oleada fue muy diverso (bastante superior en España), y acabó igualándose en las oleadas sucesivas. Si cambiamos de continente y nos fijamos en Uruguay, también veremos cómo unas medidas restrictivas ligeras comparadas con el entorno se correspondieron con una baja tasa de incidencia de la enfermedad en los primeros meses, y, en cambio, en el 2021 su tasa de muertos ha sido de las más altas. Es decir, resulta difícil establecer una correlación directa entre el carácter más o menos extremo de las medidas limitadoras de los movimientos y de los contactos sociales y los niveles de incidencia de la pandemia en cada país. Roché, S (2020) nos avanza que la única correlación demostrable es la cultura democrática de las élites políticas. Según Roché, los países con sistemas políticos en qué los gobernantes y los ciudadanos están muy alejados y alejados, en que hay bajos niveles de participación política y deficiencias del Estado de derecho se habría tendido a limitar en mayor medida las libertades. Pero habría que matizar que no sólo es la cultura de las élites políticas, sino la cultura de la población de cada país la que favorece las limitaciones de derechos. Si las élites políticas presagiaran un gran rechazo por parte de la población, muy probablemente no se atreverían a adoptarlas y ejecutarlas.

Tenemos un ejemplo clarísimo en el caso, ya

fecha 27 de abril de 2021.

3 Vid. fuente citada en la nota anterior. 
citado, de Suecia. La inexistencia de limitaciones de movimiento severas ha sido muy bien acogida por la población, que, posiblemente, hubiera reaccionado negativamente en caso de medidas más intrusivas. En los Países Bajos, la declaración del estado de alarma en enero de 2021 ha provocado una oleada de protestas (e incluso de violencia) contra la policía e incluso contra establecimientos sanitarios, mientras que en España una declaración del estado de alarma de ocho meses (septiembre del 2020 a mayo del 2021) no ha despertado más que alguna muy leve (casi imperceptible) protesta. Sin, duda, por ello los gobernantes neerlandeses tardaron mucho más a declarar el estado de alarma: porque conocían el poco nivel de tolerancia de su población para con este tipo de medidas.

\section{LA DELINCUENCIA EN TIEMPOS DE PANDEMIA}

Una crisis del nivel de una pandemia como el Covid19 tiene que afectar necesariamente tanto a la delincuencia como al orden en los países afectados. La afectación tiene mucho que ver con las medidas adoptadas para luchar contra el virus. Si la circulación por los espacios públicos se encuentra restringida, hasta el punto de que la ciudadanía puede ser denunciada y sancionada en caso de frecuentarlos sin una causa de justificación suficiente, las posibilidades de que se cometan delitos en ellos se reducen exponencialmente. No va a haber hurtos ni robos, si no hay a quién sustraerle nada; las lesiones y homicidios se van a reducir a mínimos si prácticamente no se encuentran personas en la calle. Lo mismo podemos decir del consumo y tráfico de drogas y de otros tipos de delitos. Así lo confirmaron los datos en muchos casos. En términos globales la delincuencia experimentó un gran descenso. Veamos, por ejemplo, la evolución interanual de la delincuencia global en España, Francia e Inglaterra y País de Gales:

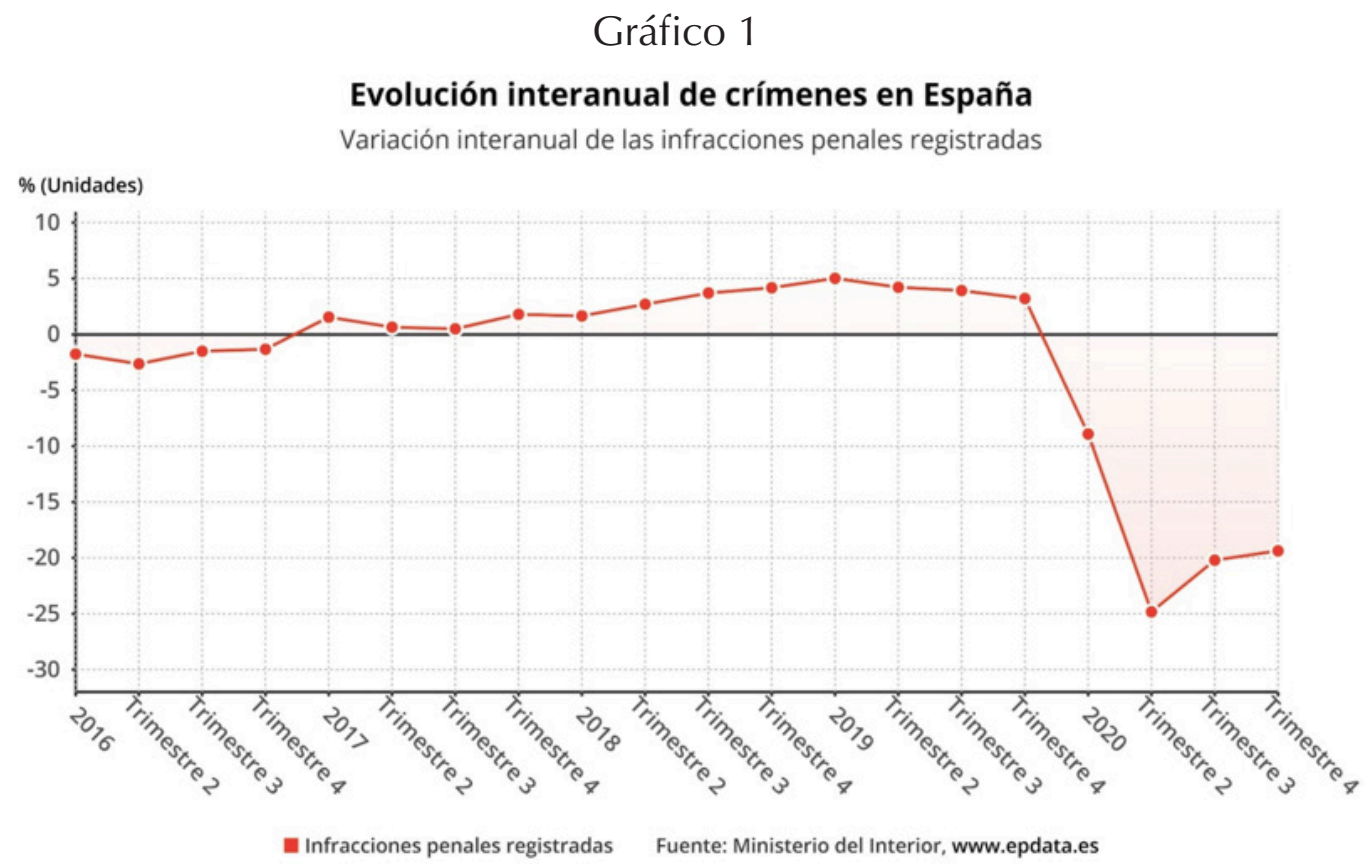

La policía en la primera línea contra la pandemia: reflexiones sobre un papel distorsionado. PP. 59-82 
Gráfico 2

\section{Evolución interanual de la delincuencia en Francia}

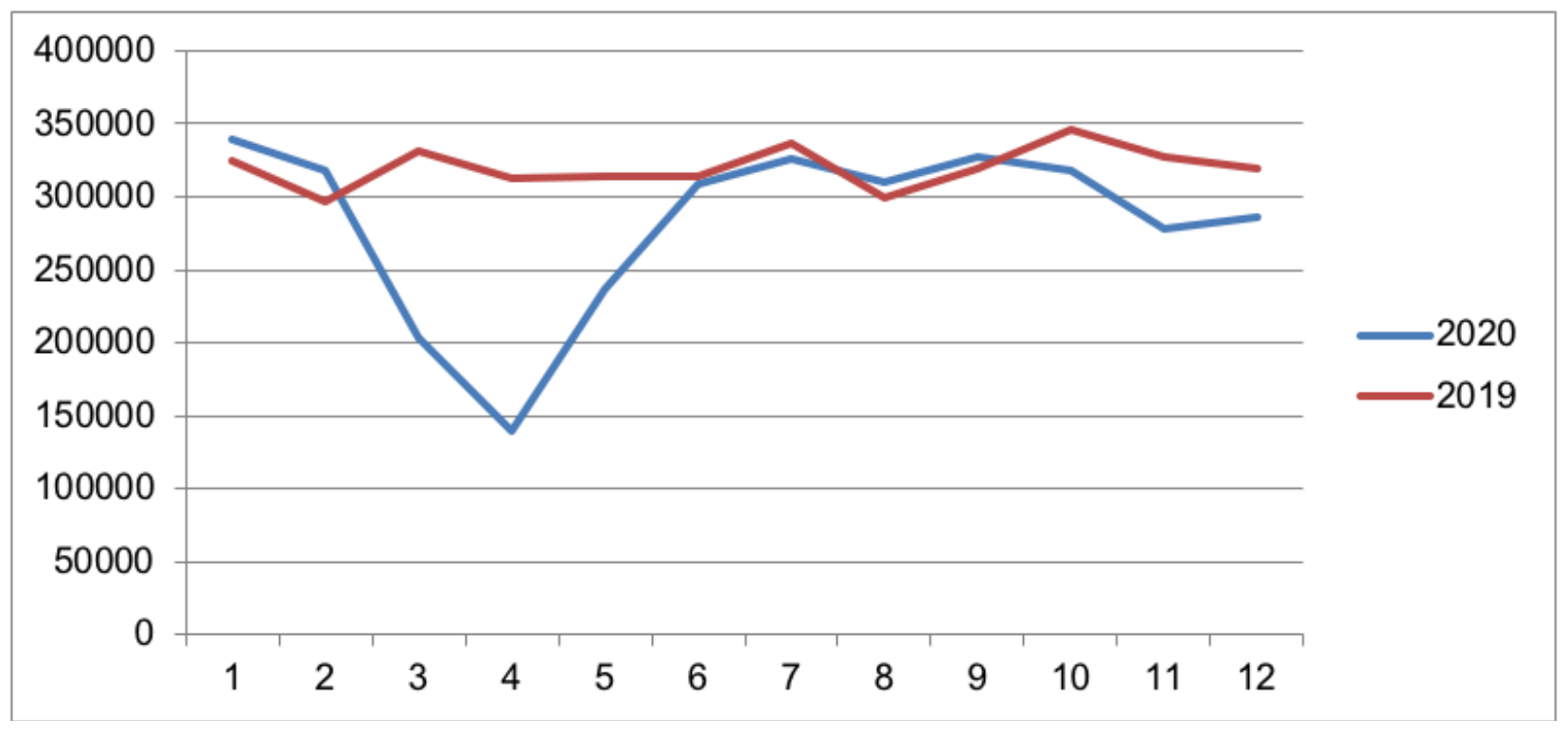

Gráfico 3

Evolución del delito en Inglaterra y País de Gales 2019-2020

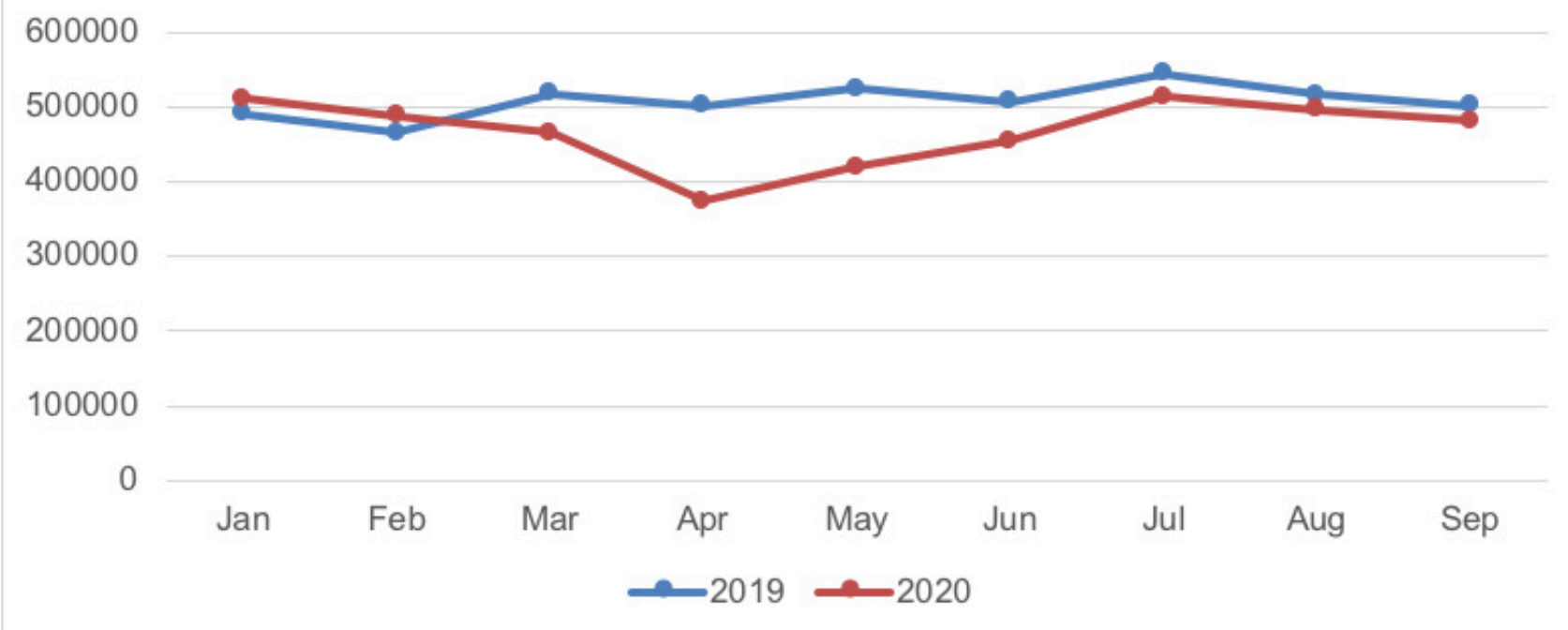


Como puede observarse en los tres casos el período de confinamiento coincide con un descenso notable de la delincuencia, descenso que se mantiene, aunque atenuado, en los meses posteriores en España, pero que vuelve rápidamente a la situación previa en Francia e Inglaterra.

Hay dos casos que resaltan notablemente como excepciones a lo que se acaba de decir. En primer lugar, con algunos matices, México, donde los homicidios descendieron de manera escasamente significativa en los primeros meses de pandemia (de manera que el período interanual de julio de 2019 a junio de 2020, incluso experimentaba un incremento del $1,2 \%)^{4}$, aunque sí disminuyeron notablemente los robos a transeúntes en el citado período interanual (julio 2019-junio 2020) (-32\%), en negocios $(-21 \%)$, de coches $(-23 \%)$ así como los robos en domicilio $(-31 \%)$. Una causa, no menor, del poco impacto en los homicidios y el narcomenudeo $(-0,2 \% \text { en la interanual })^{5}$ la podemos encontrar en el enquistado problema del narcotráfico y la violencia asociada al mismo. Es fácil imaginar que el narcotráfico, bajo el control del cual está buena parte del territorio, no se deja amedrentar por las medidas limitativas de derechos para combatir la pandemia. El mantenimiento de los delitos violentos en tiempos de pandemia sirve para confirmar el carácter de estado fallido que algunos le atribuyen a México (Barrón, M.G., 2015; Flores, C.A., 2009) debido al hecho de

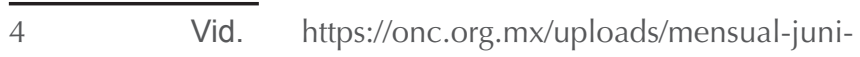
o2020-D.pdf

5 Vid. Para todos los datos mencionados la fuente citada en la nota anterior. que existen territorios en qué el poder público es incapaz de mantener la ley. No obstante, hay que reseñar que los secuestros del primer semestre de 2020 fueron notablemente inferiores al mismo semestre del año anterior, 610 por 1015 el año anterior 6 . Habría que ver hasta qué punto fue la pandemia la causa de ello, pero puede pensarse que las dificultades de movilidad y alguna reticencia al contacto con terceros pudieran haber influido.

En estos territorios también se ha evidenciado en este período como los cárteles suplantaban al Estado no sólo en el uso de la fuerza, sino también en el apoyo a la población, repartiendo alimentos y medicamentos entre los sectores necesitados: Esta práctica no es exclusiva de México y la pudimos observar en el mismo período en diversas regiones italianas practicada por las diferentes ramificaciones de la mafia italiana. De esta manera, la delincuencia organizada pretende ganarse la simpatía de sectores desfavorecidos de la población, que, muy probablemente, acabarán dependiendo de ellos y constituyendo bolsas de protección y refugio, que harán más difícil la persecución de sus crímenes.

En los Estados Unidos de América, el incremento en la venta de armas, así como el estrés provocado por la propia pandemia y las medidas consecuencia de ella, unido a una cierta contestación social que ha implicado una resistencia a cumplir las normas de confinamiento y a usar igualmente los espacios públicos nos pueden explicar la razón por la cual algunas grandes ciudades americanas

6 Vid. www.altoalsecuestro.com.mx/estadistica 
experimentaron en tiempos de pandemia un incremento de los homicidios y los delitos violentos ${ }^{7}$. Así, por ejemplo, sorprendentemente en este contexto, Nueva York, Los Angeles y San Francisco registraron más de un 30\% de incremento en el número de homicidios durante todo el año 2020, mientras Chicago, Portland, Boston, Nueva Orleans y Seattle se situaron por encima del $50 \%$ de incremento, casi en el $75 \%$ en el último caso ${ }^{8}$.

Pero existe también otra cara de la delincuencia en tiempos de pandemia. Si se reduce en los lugares dónde ha dejado de haber personas, es lógico pensar que aumente en los ámbitos en qué se hallen y se relacionen las personas con más intensidad. La inmensa mayoría de las medidas adoptadas llevaron, necesariamente, a que las personas pasaran más tiempo en sus domicilios compartiendo espacio y tiempo con sus seres más íntimos, con lo cual es imaginable que los delitos entre ellos (violencia doméstica y machista) incrementaran su presencia, ya que las oportunidades para ello aumentaron enormemente. La violencia tanto física, como psíquica o sexual contra las mujeres y otros miembros de la unidad familiar ha registrado un incremento notable (Interpol, noviembre 2020). Los datos así parecen confirmarlo, aunque hay que leerlos bien para entenderlos. En algunos casos las denuncias de delitos

$7 \quad$ Es preciso advertir, sin embargo, que la introducción de un nuevo sistema de recuento por parte del FBI puede haber influido en las dimensiones del aumento detectado (vid. https://www.nytimes.com/2021/03/16/upshot/murder-rate-usa.html?smid=tw-share ).

8 Vid. https://www.statista.com/chart/23905/change-in-homicides-in-us-cities/ contra las mujeres no aumentan, pero sí lo hacen el número de llamadas por parte de estas a centros de asistencia y apoyo en casos de víctimas de violencia machista y doméstica (como ha manifestado, entre otros, la National Commission on Covid-19 and Criminal Justice, de los Estados Unidos de América -en un 8,1\%- y Naciones Unidas en relación a sus 193 estados miembros- en un 20\%- ${ }^{-}$). Es comprensible que, dada la persistencia tanto de la pandemia, como de las medidas que obligan a pasar mucho más tiempo en casa, las víctimas de violencia que siguen viviendo con el agresor y que, en algunos casos, tienen algún tipo de dependencia económica de él, consideren arriesgado denunciar los hechos ante la policía y encuentren más plausible solicitar ayuda en los citados centros. En todo caso, estos casos muestran la necesidad de que la policía proteja a los grupos más vulnerables de las situaciones de indefensión en que se pueden encontrar (HMICFRS, 2021).

Otro de los ámbitos en qué se ha incrementado la presencia humana es el ciberespacio. Al tener restringida la movilidad, la mayoría de las personas han incrementado su presencia en internet y en las redes sociales, bien sea para relacionarse con otros, para llevar a cabo la gestión de sus asuntos, adquirir productos o servicios o llevar a cabo sus tareas profesionales en línea, lo que se ha dado en llamar teletrabajo. Si recordamos la teoría de las actividades rutinarias de Felson y Cohen (1980) y los principios en que se sustenta, para

9 Vid. https://theconversation.com/domestic-violence-calls-for-help-increased-during-the-pandemic-but-theanswers-havent-gotten-any-easier-156683 
que se produzca el delito es necesario, entre otras cosas, que haya un objeto apetecible y éste los encontraremos con mucha más probabilidad allá donde las personas Ilevan a cabo sus actividades. Es decir, el incremento de actividades digitales ha de significar, necesariamente un incremento de fraudes, estafas, abusos sexuales, pedofilia, stalking, etc. en el ciberespacio.

Otro ámbito específico en qué la pandemia ha estimulado la delincuencia es el de los productos farmacéuticos falsificados o fraudulentos. La búsqueda desesperada de remedios contra el virus facilita la salida de semejantes productos con unos réditos no menospreciables. (Interpol, noviembre 2020). Obviamente los intentos de contagiar la enfermedad a otros también pueden considerarse como una actividad delictiva de nuevo cuño.

\section{¿Existe un rol para la policía? Afectaciones de la pandemia en la policía}

Anteriormente hemos visto que, aunque una pandemia es una crisis sanitaria, hay actores no sanitarios que pueden tener un papel, entre los cuáles se encuentra la Policía teniendo en cuenta que una pandemia puede considerarse una amenaza existencial fundamental (Sheptycki, J., 2020). Incluso algunos creen razonable otorgarle un rol de cierto protagonismo al Ejército y no únicamente en tareas de apoyo a las autoridades sanitarias, circunstancia que tiene sentido y permite aprovechar los recursos que el Ejercito tiene para situaciones de emergencia, sino incluso en la aplicación de la ley y el mantenimiento del orden público (España ha sido un ejemplo claro). No, parece, sin embargo, que éstas últimas sean funciones del Ejército en estados democráticos, ya que la crisis es sanitaria no de seguridad del Estado, los que están en riesgo son los ciudadanos, no la patria. Por otra parte, una militarización de la respuesta a este tipo de crisis ha evidenciado que provoca reticencias y movimientos de protesta (Laufs, J. y Waseem, Z., 2020).

Pero, volvamos a la Policía. Es evidente que ha de tener un rol en la lucha contra la pandemia. A los pocos días de declararse la situación de excepcionalidad en todo el mundo, el 26 de marzo de 2020, Interpol publicaba un documento titulado "Pandemia de Covid19. Directrices para las fuerzas del orden" 10 . Como muy acertadamente señala Sheptycki, J. $(2020,158)$ la actual pandemia es el "primer acontecimiento policial global", en el sentido de que prácticamente todos los cuerpos policiales del mundo fueron movilizados en el mismo momento debido al mismo incidente. Por eso tiene mucho sentido el documento de Interpol. Este documento empieza con recomendaciones específicas para que los policías actúen de manera segura en contextos con un peligro grande de contagio. Parece una buena idea, lo primero que tiene que hacer la Policía para poder prestar el servicio público que se espera de ella es mantener la salud. Un/a policía contagiado/a de Covid es una persona que no puede prestar ningún tipo de servicio y, además, puede implicar la cuarentena de las personas de su entorno laboral, circunstancia que mermará la capacidad de acción de la

10 Puede consultarse esta edición, así como la segunda, de noviembre de 2020 en https://www.interpol.int/es/Como-trabajamos/COVID-19/COVID-19-Protejase 
organización en un momento de demanda de servicios, ya que, por ejemplo, las denuncias telefónicas de infracciones de las normas antipandemia incrementaron notablemente el número de llamadas al 911 (Jennings, W.G., y Pérez, N.M., 2020), aunque es cierto que las Ilamadas relativas a delitos y otros incidentes de seguridad disminuyeron exponencialmente (NENA, 2020). Así, las primeras medidas que ha de tomar la policía han de ir destinadas a protegerse de la enfermedad para poder estar en condiciones de proteger a la ciudadanía (Aston, L., 2020; Jennings, W.G. y Pérez, N.M., 2020, también se pronuncian en esta dirección). Los responsables de personal de las organizaciones policiales han tenido que hacer muchísimos equilibrios para mantener un servicio mínimo suficiente, ya que una demanda cualitativamente importante coincidía con numerosos efectivos de baja por contagio o por cuarentena.

Un contexto como el actual tiene, sin duda, que derivar en un mandato hacia los poderes públicos de facilitar las condiciones sanitarias necesarias para que los/las policías puedan trabajar en las condiciones higiénicas suficientes, que les den ciertas garantías de no contagiarse. Esto implica facilitar las mascarillas (tapa-bocas en México), equipos de protección individual (EPIs), los hidrogeles, la desinfección de los equipos de trabajo, la realización, en su caso, de PCRs y todo aquello que se considere necesario para ello, circunstancia que no se dio prácticamente en ningún país, dejando a los agentes de policía un tanto desamparados ante el virus que ha causado la pandemia.

Una vez realizadas las recomendaciones sanitarias de seguridad, el documento de
Interpol, pasaba a realizar recomendaciones prácticas sobre cuáles pueden ser los ámbitos más sensibles de intervención policial: la violencia doméstica, abusos sexuales de menores, protección de centros sanitarios, de zonas de confinamiento, fugas de presos, garantizar los suministros médicos, la necesidad de cooperar con todos los actores, públicos y privados, la necesaria vigilancia del ciberespacio, así como la importancia de mantener una comunicación fluida, directa y actualizada con el público. También hay referencias al mantenimiento del orden público, muy adecuadas teniendo en cuenta los incidentes de protesta que han provocado las medidas antipandemia, incluso con cariz violento (Campedelli, G.M., y D'Orsogna, M.R., 2021), aunque no entra en detalle sobre como ejercerlo para minimizar los contagios entre los asistentes. Se trata de unos cuantos consejos simples, directos, sin entrar en consideraciones estratégicas o éticas.

Aunque no apuntan directamente a cuestiones estratégicas o de modelo (no es una función de Interpol), sí que acaba incidiendo en una función importante de la policía en una época de transformaciones tan grandes como implica una pandemia. Acabamos de ver que la delincuencia ha mutado en función de las actividades de la ciudadanía y de los lugares dónde se encuentra. Pues bien, la policía ha de orientar al público en esta dirección. En tiempos de grandes incertidumbres es importante que una institución dedicada al mantenimiento de la seguridad pueda acompañar a las personas, informándolas de los nuevos riesgos, así como de las medidas de prevención que tendrían que adoptar para no ser víctima de ellos (Guillén, F., 2020b). 
Pese a su simplicidad, el documento de Interpol acierta señalando la comunicación con el público como una función fundamental de la policía en tiempos de pandemia. Son tiempos de incertezas, de informaciones confusas y contradictorias (e incluso de noticias falsas) y de aparición de riesgos desconocidos hasta el momento. Tiene sentido que una institución que representa al Estado como ninguna otra y que está de servició 24 horas diarias los 365 días del año, intente aportar certidumbre y consejos útiles sobre las conductas más adecuadas. La Policía puede ejercer esa función de guía tan necesaria en tiempos de desorientación como son los de pandemia. Puede ser una gran contribución a la seguridad ciudadana, que haga disminuir el pánico e incluso los desórdenes públicos. No obstante, como acertadamente señalan Jennings, W.G, y Perez, N.M, (2020), la Policía afronta muchas dificultades para establecer esta comunicación imprescindible. De entrada, porque la comunicación ha de ser también fluida internamente, informando adecuadamente a los policías sobre medidas sanitarias, iniciativas de los poderes públicos y toda la información relativa a la evolución de la pandemia. En muchos casos, los policías actuantes no disponían de la información actualizada de la situación, con lo que difícilmente podían facilitar al público los datos necesarios sobre el estado de la cuestión y las normas de conducta necesarias para hacerle frente.

En la práctica, la necesidad de la Policía, por su parte, de mantener la distancia social, por razones de seguridad sanitaria, ha influido significativamente en sus intervenciones. Así, por ejemplo, han disminuido notablemente las paradas e identificaciones en la calle, actuaciones paradigmáticas de la policía. El riesgo de contagio ha hecho reconsiderar muchas intervenciones de este tipo (Brooks, R., y López, C., 2020). Esto puede cambiar las estrategias de intervención de la policía en un futuro, quizá racionalizando más este tipo de intervenciones. Si tenemos en cuenta el alto nivel de conflictividad de estas intervenciones (Guillén, F., 2018), su ponderación puede incluso mejorar la relación con el público, así como aumentar su eficiencia (Brooks, R., y López, C., 2020). Las estrategias y tácticas de afrontar las protestas en la calle también se hubieran tenido que modificar para no contribuir a facilitar el contagio entre manifestantes. Ha sido una época con numerosas protestas y no únicamente contra las restricciones derivadas de la pandemia, ya que ha coincidido con las protestas por la muerte de George Lloyd a manos de la policía y todo el movimiento mundial de protesta (black lives matter) que se originó como consecuencia. Carbonaro, G. y Somara, S. (2020) publicaron un pequeño artículo detallando las tácticas que la policía no debiera utilizar para evitar que los manifestantes se contagiaran de manera desproporcionada, como, por ejemplo, la conducción de la masa hacia espacios estrechos para poderlos controlar mejor, o la conducción de multitud de detenidos en la misma furgoneta o su estancia en celdas de pequeñas dimensiones. Incluso la National Association of Governors de los Estados Unidos de América publicó un memorándum con recomendaciones específicas para que las intervenciones policiales en materia de orden público no favorecieran una difusión incontrolada del virus ${ }^{11}$.

$11 \quad$ Vid. https://www.nga.org/center/publications/protests-policing-covid-19/ 
Para minimizar los riesgo de contagio en sus contactos con el público, la policía ha incrementado el uso de la tecnología en su comunicación con la población, debido a la necesidad de mantener la distancia social para impedir la transmisión del virus (Wells, H., Aston, L., O'Neil, M., y Bradford,B., 2020). Por un lado, los ciudadanos han acudido menos a las comisarías de policía y, por otra, la policía, ha usado medios tecnológicos para comunicarse con el público si una actuación presencial no era absolutamente necesaria para el caso en concreto. No es un proceso que se haya iniciado con la pandemia, ya previamente la policía estaba muy presente en las redes sociales y se comunicaba a través de ellas con la población, pero, sin duda, la crisis sanitaria ha acrecentado esta tendencia y posiblemente habrá ámbitos en que se mantendrá en el futuro. Esta nueva realidad, que ha llegado para consolidarse, reconfigurará la relación de la policía y el público, precisamente en momentos en que la idea de proximidad entre unos y otros está muy presente como elemento legitimador y de eficacia de la labor policial.

¿Cómo se tendrá que plasmar la proximidad a través de la tecnología? Probablemente es posible ser próximo a través del mundo digital, pero aún no sabemos cómo se tiene que concretar esta proximidad digital. Constituirá, sin duda, un reto para la policía conseguirla (Wells, H., et al., 2020). Reto de gran importancia dado que la confianza de la población en la Policía depende mucho de la comunicación y de la proximidad, y, por su parte, la seguridad subjetiva de la población depende en buena parte de su confianza en la Policía (Guillén, F., 2020a).
Una aplicación estricta y poco reflexiva de las normas antipandemia incrementa las desigualdades.

La normativa elaborada para frenar la expansión de la pandemia es, en principio, aplicable a todo el mundo por igual, y su aplicación estricta tendría que estar pensada para favorecer el bien público. No obstante, las normas nunca han sido elaboradas para que una gran cantidad de la población fuera denunciada, sino para que su existencia facilitara comportamientos ciudadanos adecuados o normativos (Hough,M., 2021; Tyler, T.R., 1996). Scheptycki, (2020), precisamente hablando de la normativa antipandemia, nos viene a decir que una aplicación intensa de la legislación es contraria a un sistema democrático de policía y no favorece el bien común. Además, un análisis un poco más profundo de la situación nos saca del error de pensar que la legislación aprobada para combatir la expansión de la pandemia afecta a todo el mundo por igual. No todos tienen la misma facilidad o las mismas dificultades para cumplir dicha normativa. Así, aquellas personas que tienen empleos estables o negocios que les permiten continuar la actividad teletrabajando y, además, poseen residencias espaciosas, incluso con espacios exteriores, se van a encontrar con una necesidad muy inferior de transgredir la norma y abandonar el domicilio fuera de los supuestos previstos. Tienen aire fresco en sus espacios exteriores y sus ingresos más o menos asegurados. En cambio, aquellas personas que tienen empleos precarios, que si no trabajan efectivamente no reciben remuneración y que, además, habitan en viviendas de pocos metros cuadrados sin espacios exteriores y muchos miembros de la unidad de convivencia, tienen muchísima 
más necesidad de abandonar el domicilio. Si a esto añadimos las dificultades de la Policía para denunciar y sancionar a las personas con un estatus socio-político alto (en España dos ex-presidentes del Gobierno incumplieron de manera visible las normas de confinamiento y no fueron objeto de denuncia alguna), acabaremos concluyendo que inevitablemente serán los grupos de población más vulnerables los que en la práctica serán objeto de las denuncias y las sanciones, empeorando aún más su grado de vulnerabilidad (Hough, M., 2021).

Aston et al. (2020) nos muestran como la intensidad de la aplicación de la normativa anticovid19 no ha sido la misma en todo el territorio. Las zonas pobladas por personas más desfavorecidas sufrieron una intervención policial mucho más intensa que las pobladas por clases acomodadas, citan expresamente los casos de Madrid en España y de las banlieues en Francia. En el caso de Madrid, las denuncias escasearon en el barrio de Salamanca (a pesar de celebración de protestas sin respetar la distancia de seguridad y sin la preceptiva mascarilla -tapa bocas-) y fueron más numerosas en barrios más desfavorecidos. Brooks, R. y López, C. (2020) nos apuntan las desigualdades en la aplicación de la ley en los Estados Unidos de América y señalan como la normativa sanitaria actual es aplicada de manera más intensa en las comunidades más vulnerables (afroamericanos e hispanos). Por ello recomiendan que"..siempre que sea posible, la policía tendría que orientar su actividad a promover el cumplimiento voluntario de las órdenes de permanecer en casa y de cuarentena, facilitando información y apoyo mucho más que adoptar una actitud punitiva" (Brooks, R., y López, C., 2020, 17).
Por ello, además, estas autoras recomiendan a las autoridades considerar la posibilidad de, a la hora de hacer efectivas las sanciones derivadas de las denuncias policiales por incumplimiento de las normas sanitarias, moderar la cantidad impuesta como multa en función de la capacidad económica de los sujetos afectados. En Inglaterra y País de Gales se calcula que las minorías étnicas tuvieron un 54\% más de posibilidades de ser objeto de denuncia que la mayoría blanca (Hough, M., 2021).

La desigualdad de género también ha sido suficientemente documentada, no únicamente debido al incremento de la violencia por parte de la pareja que se ha citado más arriba, sino por la precariedad laboral de muchas mujeres que trabajan en el sector de servicios domésticos con contratos precarios o formalmente inexistentes, que han tenido que seguir trabajando para mantener la remuneración y, al mismo tiempo, han visto alargada su jornada laboral para cuidar otras personas que estaban en cuarentena o confinadas, aumentado su riesgo de contagio y, además, con altas posibilidades de ser denunciadas en su trayectoria al lugar de trabajo (CNDC, 2020). De hecho, a los pocos días de iniciado el confinamiento, el World Economic Forum ya vaticinó que la situación perjudicaría especialmente a las mujeres ${ }^{12}$.

En otros contextos es necesario, además, tener en cuenta otras coyunturas. Así, por ejemplo, en México, el Estado es incapaz de hacer respetar la ley en importantes partes del territorio,

12 Vid. https://www.weforum.org/agenda/2020/03/thecoronavirus-fallout-may-be-worse-for-women-than-men-hereswhyl 
existiendo una imagen de impunidad del crimen organizado. En semejante escenario, la idea de una aplicación de la normativa COVID-19 a los habituales se puede hacer incluso mucho más presente y profundizar más en el alejamiento del Estado de amplios sectores de población, y más, si como también se ha señalado, el crimen organizado facilita a algunos las ayudas que el Estado es incapaz de proporcionar.

Obviamente la policía no puede ignorar la normativa cuando se encuentre con personas pertenecientes a grupos vulnerables o desfavorecidos y permitirles cualquier incumplimiento de la normativa sin tener en consideración los riesgos sanitarios derivados de ello. Simplemente se trata de evidenciar que el cumplimiento de la normativa anti-covid no resulta igual de simple para todo el mundo y que una aplicación mecánica y estricta puede contribuir a aumentar las desigualdades. En este caso la igualdad ante la ley está muy lejos de constituir una realidad fehaciente.

\section{Las diferentes respuestas de la policía en el mundo. Los condicionantes y factores en la trastienda.}

Hemos visto que la normativa antipandemia, aunque ha implicado siempre medidas restrictivas de la movilidad y de los contactos sociales, ha presentado diferencias notables en algunos países. Es cierto que se podría argumentar que las diferencias radicales han sido pocas y que la diversidad se ha centrado en modalidades diversas del confinamiento. Pues bien, en el ámbito de su aplicación concreta por parte de las diversas organizaciones policiales sí que las diferencias se han disparado. Ha habido algunas que rápidamente sobrepasaron los centenares de miles de denuncias y millares de detenidos (Francia, España ${ }^{13}$ e Italia ${ }^{14}$ ), mientras que otras, especialmente aquellas del Reino Unido, después de más de un año no han alcanzado las 100.000 denuncias. Inglaterra llevaba 99.742 en abril de 202115, mientras Escocia, $\left(15.284^{16}\right)$ y País de Gales $\left(10.580^{17}\right)$ se quedaban lejos de esta cifra. Posiblemente, y por eso destacamos estos dos grupos aquí, esto tenga que ver con dos estrategias totalmente diferentes, fruto de culturas políticas y modelos policiales notablemente diversos (Guillén,F., 2015 y 2016). Así, mientras los países del Sur de Europa han seguido tradicionalmente un modelo de policía gubernativa, derivado del modelo de la Revolución Francesa, las Islas británicas han seguido un modelo de policía comunitaria, uno de cuyos pilares ha sido y es el policing by consent. Es decir, el modelo

13 En España se habían realizado 1.021.773 propuestas de sanción y detenido 8.442 personas a 20 de mayo de 2020 (http://www.interior.gob.es/ca/prensa/noticias/-/asset_publisher/GHU8Ap6ztgsg/content/id/11908410)

14 El Ministerio del Interior italiano afirma haber controlado a 12.360 .197 personas entre el 11 de marzo y el 3 de mayo de 2020, de las cuales 419.108 fueron denunciadas por incumplimiento de al normativa anticrisis (https://www.interno. gov.it/sites/default/files/2020-08/dossier_viminale_2020.pdf )

15 Vid. https://news.npcc.police.uk/releases/update-on-coronavirus-fpns-issued-by-police-april-2021-embargoed-until-0001-thursday-29-april-2021

16 Vid. https://www.scotland.police.uk/about-us/covid-19-police-scotland-response/enforcement-and-response-data/ Los datos hacen referencia al período que va del 27 de marzo de 2020 al 21 de abri de 2021.

17 Vid. https://news.npcc.police.uk/releases/update-on-coronavirus-fpns-issued-by-police-april-2021-embargoed-until-0001-thursday-29-april-2021 
policial ha partido (con la excepción de Irlanda del Norte debido al grave conflicto interno Guillén, F., 2016-) de la idea de utilizar la fuerza como último recurso e intentar imponer el cumplimiento normativo a través de la aceptación, del consentimiento del público. En este contexto una tarea fundamental de la policía es convencer al público de la necesidad de cumplir la normativa y, sólo en casos muy extremos, acabar imponiéndola de manera coactiva.

Es importante remarcar que no se pretende en este artículo hacer un juicio de valor sobre el modelo policial británico y el conocido como modelo tradicional (gubernativo) en Europa continental (Guillén, F, 2015 y 2016). Sería un objetivo imposible porque no existen modelos inferiores o superiores, sino que los modelos reflejan las necesidades y los valores de cada sociedad. Quede, pues, claro que no estamos contraponiendo el modelo gubernativo continental (pretendidamente perverso) al modelo británico (teórico modelo ideal). Lo que se pretende hacer es constatar que las diversas estrategias se corresponden con dos culturas políticas e ideales de la policía muy diferentes pero coherentes en sí mismas.

En el caso británico, las organizaciones policiales diseñaron una estrategia debidamente explicada internamente. El Consejo Nacional de Jefes de Policía y la Academia Superior de policía publicaron guías de actuación, que fueron hechas públicas inmediatamente ${ }^{18}$. Era

18 Vid. https://www.police.uk/advice/advice-and-information/c19/coronavirus-covid-19/coronavirus-covid-19-police-powers/ la conocida como estrategia de las cuatro " $\mathrm{e}$ "s: engage, explain, encourage and execute. Se pide a los agentes de base que se impliquen con la gente, que les expliquen la normativa y sus razones, que los animen a cumplirla y, en caso de incumplimiento, denuncien. Los mismos documentos recomiendan expresamente denunciar únicamente en caso de conductas reincidentes o que pongan en grave peligro la salud pública (fiestas con multitud de personas, etc.). Es cierto que no deja de ser un eslogan, además, de cumplimiento difícil ya que la normativa ha ido cambiando constantemente y ,como se ha dicho, las posibilidades de explicarla de manera adecuada y convincente no han sido muchas. Sin embargo, lo que es importante es constatar que en todos los documentos se destaca que el objetivo de todo este despliegue es continuar manteniendo a la población segura y, en ningún momento, aparecen visos de que lo importante sea mantener el poder del Estado ni se consideran positivas las denuncias en sí mismas. Consecuentemente con este mensaje el número de denuncias es muy bajo, ya que no se alienta a los agentes a denunciar a troche y moche. Obviamente, en la práctica también se han producido intervenciones policiales ridículas e inadecuadas. Por ejemplo, en algunas partes del país la Policía ha estado parando a ciudadanos porque hacían ejercicio en campo abierto, conducta que no era contraria a las regulaciones legales, sino simplemente a las recomendaciones del Gobierno, que no tienen, obviamente, fuerza de obligar (Hough, M., 2021).

En cambio, los modelos gubernativos suelen estar más distanciados de la población y no tienen demasiado inconveniente en aplicar 
coactivamente la normativa. La legitimidad les viene no tanto del consenso del público, como sucede en el modelo anglosajón, como del respeto de la legalidad y el seguir las instrucciones marcadas por el gobierno establecido siguiendo los procedimientos constitucionales (Guillén,F., 2015 y 2016). Así, en los casos de Italia, España y Francia se produjeron discursos públicos que alentaban a las fuerzas del orden a denunciar toda conducta infractora de la normativa antipandemia. Incluso en Francia el ministro del interior emitió un tweet vanagloriándose de los más de dos millones de denuncias administrativas realizadas por la policía francesa, como si la cifra en sí misma constituyera un éxito. Aunque hubo algunas quejas por algunas intervenciones policiales excesivas, la población las valoró, en general, de manera positiva, incluso frecuentemente la policía recibía denuncias de violaciones con demandas de actuaciones más drásticas ${ }^{19}$. Es decir, está aplicación masiva de la normativa se realiza en un contexto muy favorable y comprensivo con este tipo de actuaciones (Hough, M., 2021). De todas maneras, el paso del tiempo ha ido desgastando la popularidad de las denuncias policiales y éstas se han reducido razonablemente, centrándose en las vulneraciones que entrañaban riesgos mayores para la salud pública. En Francia ya se han llegado a producir disturbios con uso de la fuerza contra la policía y, en menor medida, también en Italia y España.

Desde las instancias oficiales se ha intentado argumentar que el carácter más drástico en la aplicación de la normativa estaba directamente relacionado con una menor disciplina en el cumplimiento de la norma de los ciudadanos de países del sur en contraposición a la disciplina centro y norte europea. El argumento era que la única manera que existía en estos países de disuadir a la población de infringir las normas que restringían la movilidad, era la amenaza efectiva de sanción (lo que en Derecho Penal se llama "certeza de la pena"). Sin embargo, si analizamos los estudios de movilidad llevados a cabo, entre otros por Google $\mathrm{e}^{20}$, a partir de los teléfonos móviles, veremos que los que tuvieron unas medidas más estrictas eran los que menos se movían y, en cambio, aquellos que registraron desde el principio una movilidad mayor adoptaron medidas menos restrictivas (Roché, S., 2020). Los datos publicados por Google hacen referencia a la movilidad en seis ámbitos: comercio (no esencial) y ocio, alimentación y farmacia, parques públicos, estaciones de medios de transporte, lugar de trabajo y lugar de residencia. La movilidad se compara (en + o en -) a la existente antes del establecimiento de las restricciones.

20 Vid. https://www.google.com/covid19/mobility/
19 En algunos casos las denuncias eran falsas y los denunciantes acababan siendo denunciados por la policía. El Ministerio del Interior informa que 5.684 personas fueron denunciadas por falses denuncias en el período marzo-junio de 2020 (https://www.interno.gov.it/sites/default/files/2020-08/ dossier_viminale_2020.pdf ) 


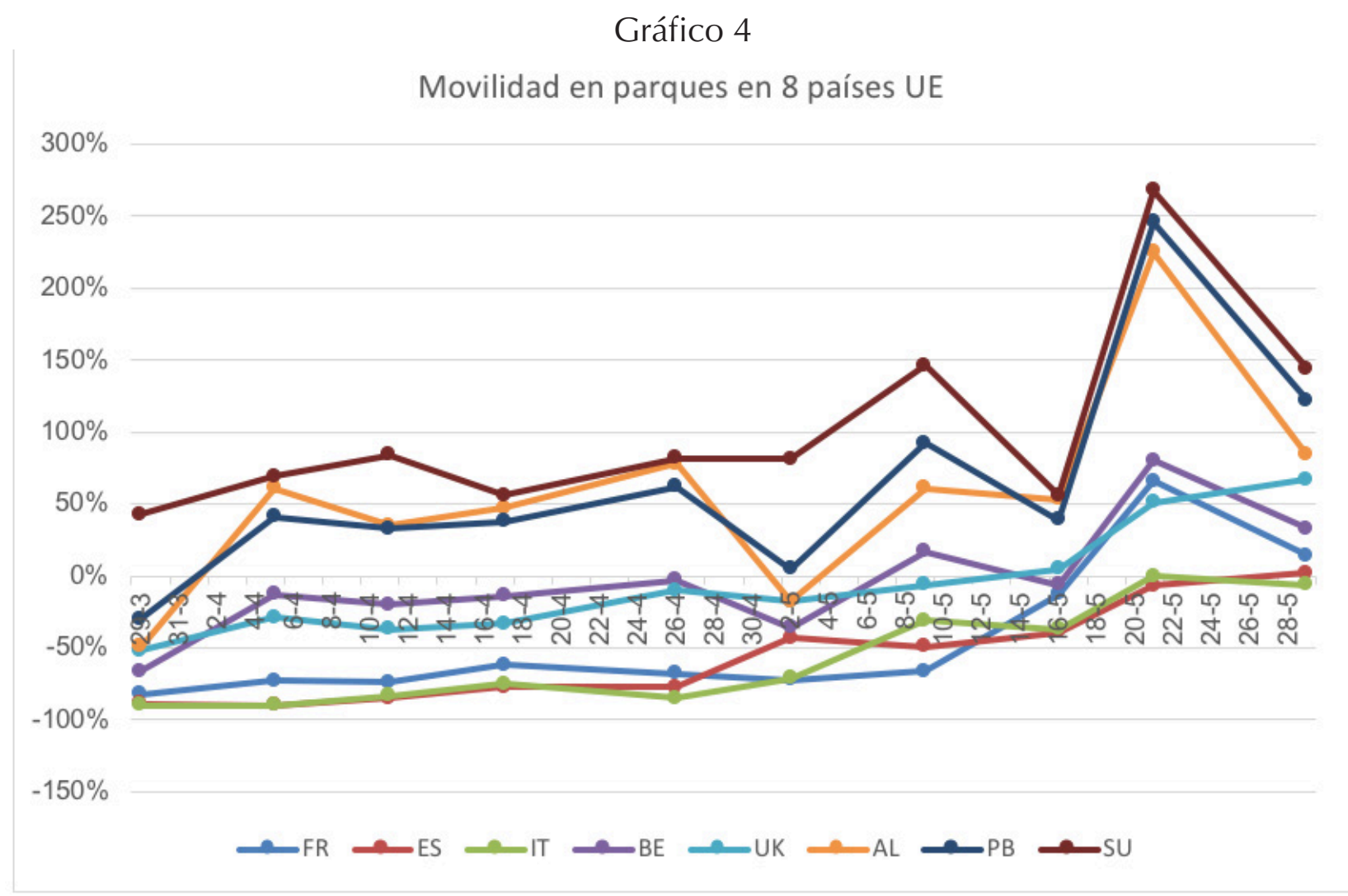

Fuente: Google. Informe de movilidad de las comunidades ante el Covid 19.

Si nos centramos, por ejemplo, en la movilidad en los parques, nos encontramos que los tres países con mayor número de denuncias por infracciones de normas antipandemia (Francia, España e Italia) son las que registran un mayor descenso de la movilidad (entre un 80 i un $90 \%$ menos de movilidad en relación al momento previo a la pandemia) desde los primeros momentos de la medición. Se puede argumentar que la razón por la que se registra una menor movilidad en los parques en estos países es, precisamente, al número de denuncias interpuestas por la policía, que, según este planteamiento, sería la razón de la formidable disminución de la movilidad. Sin embargo, para que en estos primeros momentos de la pandemia se produjera tal cantidad de denuncias la movilidad debiera haber sido muy alta, porque, si no lo fue, ¿qué conductas se sancionaron si la población en esos países apenas se movió? Si comparamos la situación con el Reino Unido, observamos descensos de la movilidad inferiores (sobre el $50 \%$ en relación a la anterior a la pandemia), y, sin embargo, el número de denuncias de la policía fue infinitamente inferior como acabamos de ver. Es cierto que en aquellos momentos las restricciones en este último país no eran tan drásticas como en los tres países con un mayor número de denuncias, con lo cual se podría jsutificar alguna parte de la diferencia. Pero, posteriormente, se fueron endureciendo, sin 
que la movilidad se redujera significativamente y las denuncias no aumentaron. Resulta difícil de explicar, que sean más denunciados por moverse en los parques públicos los ciudadanos de los países que, objetivamente, menos se movieron. Un caso diferente, y perfectamente justificable, es el de Suecia, que, contrariamente, vio incrementada la movilidad en estos espacios con respecto al momento anterior a la crisis sanitaria, debido a la inexistencia de restricciones legales para transitar por ellos, y, además, con recomendaciones de evitar lugares cerrados y concurridos. Es razonable entender que muchas personas de aquel país pudieran pensar que la mejor opción era aumentar el uso de los parques públicos, espacios más seguros para evitar los contagios.

Es decir, si se compara el nivel de movilidad de la población desde el principio en el momento del establecimiento del confinamiento y su evolución posterior no se observa ninguna influencia de las medidas más restrictivas. El primer día de confinamiento, antes de que se pudiera llevar a cabo ninguna denuncia por incumplimiento de las normas anticovid19 los niveles de movimiento en los países con restricciones más graves ya eran extremadamente bajos y se mantuvieron en un nivel similar durante las seis semanas que duró la oleada.

Si analizamos en particular el caso de España, veremos que los momentos más álgidos del número de denuncias por infracciones (sumadas las de todas las policías existentes), que podemos situar en las primeras semanas del mes de abril de 2020, también coincide con períodos de muy baja movilidad.

\section{Gráfico 5}

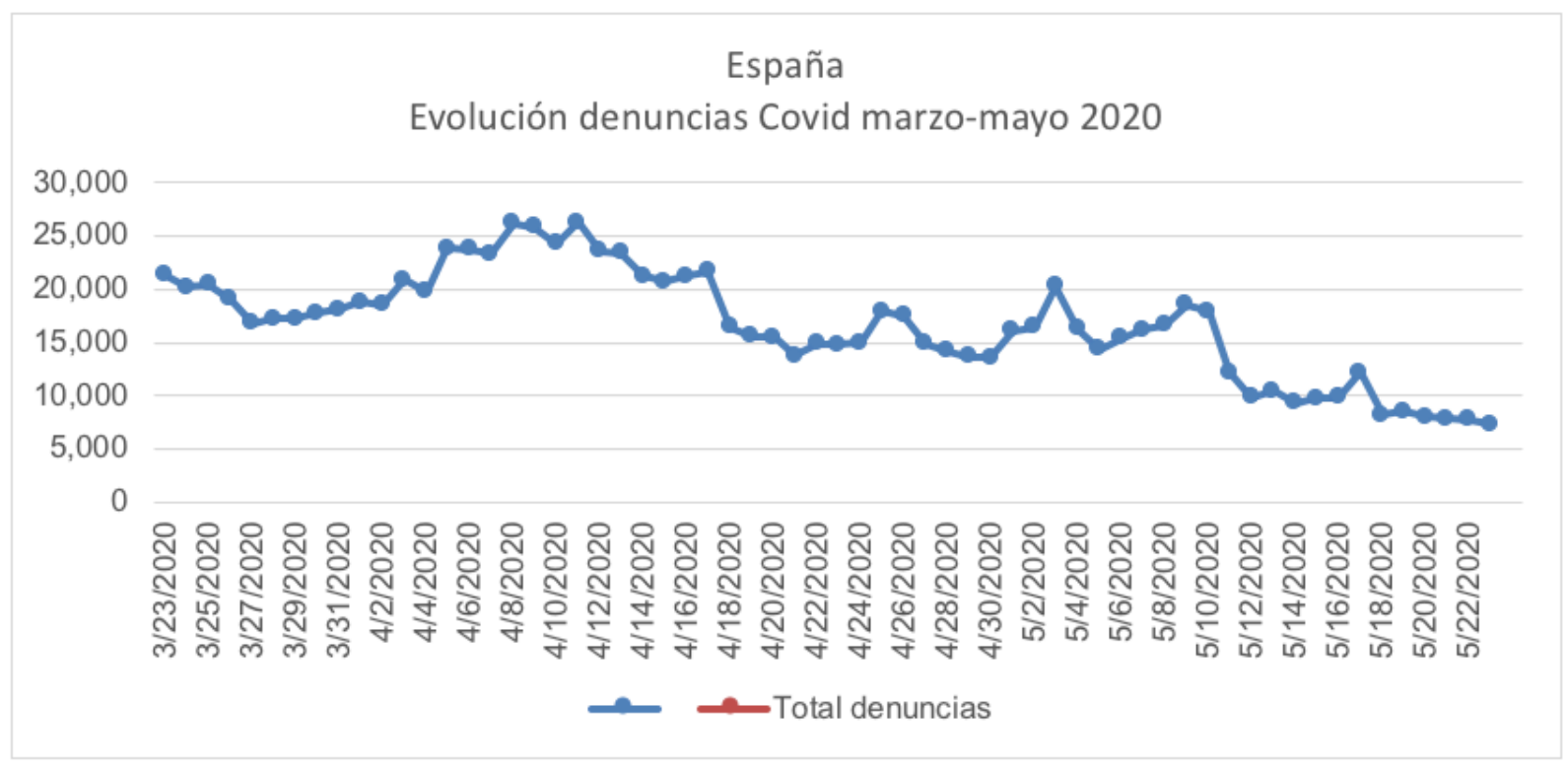

Fuente: Ministerio del Interior (ESP) 
El punto más álgido del número de denuncias de la policía se produce el 11 de abril (26.263 denuncias), que coincide (vid. Gráfica siguiente) con los momentos más bajos de lógica, por otra parte).

\section{Gráfico 6}

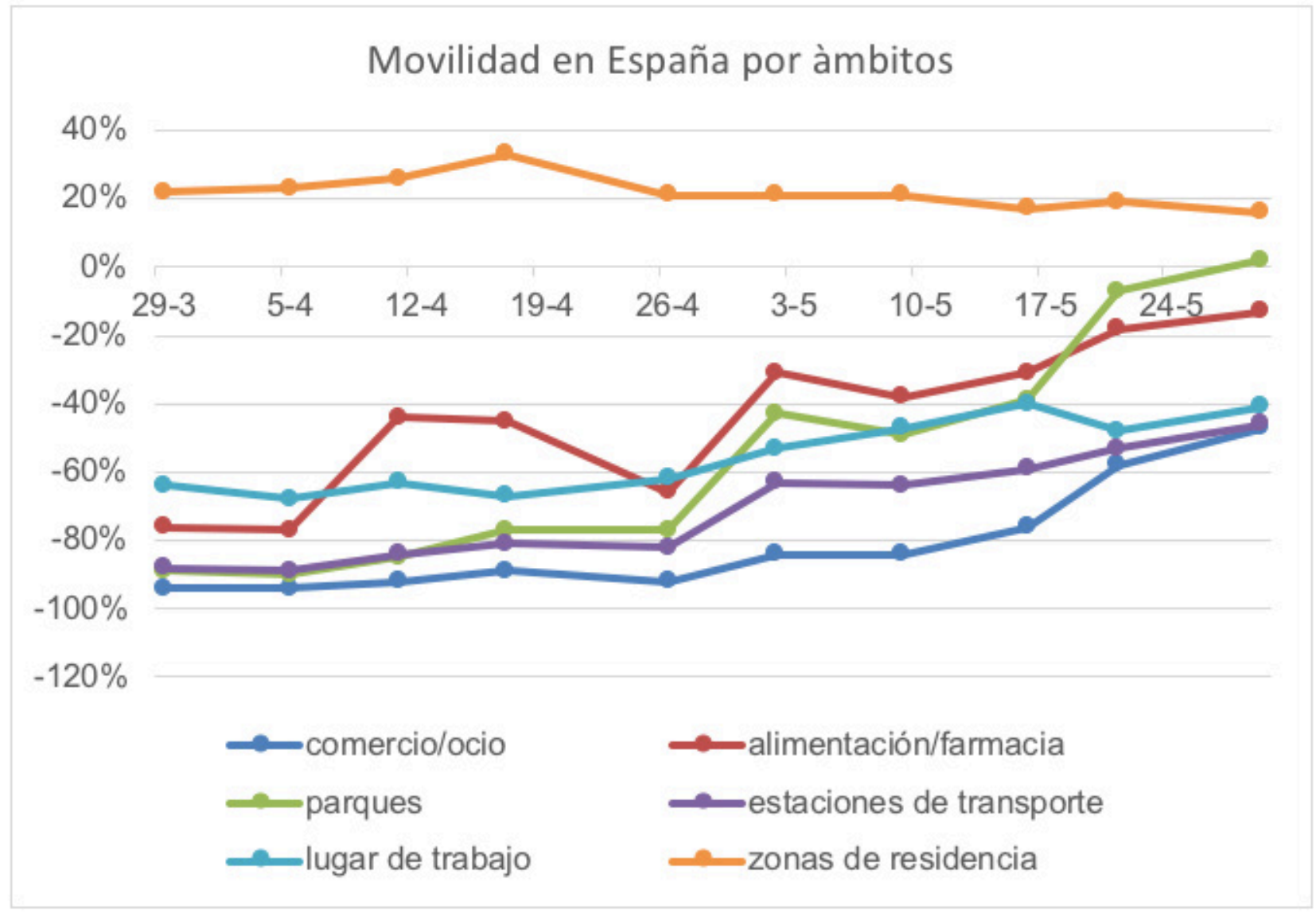

Fuente: Google. Informe de movilidad de las comunidades ante el COVID19

Estos datos muestran que la mayor o menor intensidad de la actuación policial no estuvo relacionada con la mayor o menor movilidad de la población sino con la cultura política y el modelo policial, como se ha observado con claridad en la comparación entre el caso británico y los tres países citados del Sur de Europa. movilidad (excepto en los espacios dedicados a alimentación y a farmacia, y en aquellos cercanos a la residencia habitual, circunstancia 
población (Laufs, J., y Waseem, Z., 2020). Por ello es importante definir cuál ha de ser el rol de la Policía para que esta confianza no se vea mermada $y$, en la medida de los posible, se consolide. Para proceder correctamente es conveniente volver a los orígenes y pensar cuál es la función primordial de la Policía en una sociedad democrática y cómo ha de ser su relación con la población. En una sociedad democrática el objeto prioritario de atención de los poderes públicos ha de ser la ciudadanía mucho más que la defensa del Estado y su autoridad. La Policía ha de estar concebida como una institución que protege y respeta a las personas y sus derechos. La legitimidad de las organizaciones policiales en estas sociedades no viene tanto de la ley como de su aceptación por parte de la ciudadanía (Guillén, F, 2018). Esta aceptación de la ciudadanía vendrá dada por lo justas que interprete que son sus actuaciones mucho más que por las potestades legales que aquella tenga, en función de lo que se ha venido en Ilamar justicia procedimental de la Policía (Guillén, F., 2018; Hough, M., 2021; Tyler, T.R., 2011). De hecho, la ciudadanía cumple en mayor o menor medida las normas en función de lo justas que las considere y de la opinión que tenga de aquellos que las ejecutan (Tyler,T.R., 2003). La amenaza de sanción no es suficiente para conseguir un cumplimiento masivo de las normas (Tyler, 1996).

En el contexto de una pandemia puede existir la tentación de proceder a una aplicación estricta, incluso agresiva, de la normativa destinada a frenar su expansión. Los grandes riesgos que se corren, el pánico que provoca, así como la presión sobre los actores públicos pueden llevar a una utilización muy extensiva de los poderes de coacción del Estado, normalmente a través de la Policía. Hemos visto que, en muchos casos, incluso sectores de la población así lo reclaman. Sin embargo, hay que reflexionar sobre cómo la Policía puede cumplir mejor con su finalidad originaria: proteger a la población, en este caso evitar que la enfermedad se extienda de manera descontrolada afectando multitud de ciudadanos. Si la mayoría de los ciudadanos cumple las normas de manera voluntaria cuando considera que son justas y se aplican correctamente, la Policía tendría que facilitar esta vía. No olvidemos que su objetivo último ha de ser éste: que los ciudadanos cumplan y, en consecuencia, se protejan de los riesgos de contagio. Así, es importante que los ciudadanos conozcan las normas, sus razones, los riesgos implícitos para así entender que lo más razonable sea seguir los mandatos establecidos por ellas. Una actuación abusiva o simplemente agresiva de la Policía puede evitar este proceso y posicionar al público contra ella, circunstancia que no hará sino dificultar la propensión futura al cumplimiento y puede acabar derivando en enfrentamientos. Además, si esto predispone al incumplimiento futuro, facilita que la población acabe corriendo más riesgos de los necesarios. Es decir, una aplicación indiscriminada y rígida de la normativa por parte de la Policía puede ir contra la función de la policía, ya que la población acabará estando menos protegida. Posiblemente podrán justificar un alto número de intervenciones, con multitud de denuncias, pero esto no tendrá una incidencia en el freno a la pandemia (de hecho en los países con un mayor número de denuncias no se han dado precisamente los mejores resultados en la lucha contra la pandemia). 
Es cierto que no todo el mundo está dispuesto a seguir los consejos y las explicaciones de la Policía, y que esta argumentación puede parecer naif, ya que puede ser entendida como que la Policía no debe denunciar a nadie ni usar sus potestades en ningún caso, y utilizar única y exclusivamente la palabra para aplicar la normativa en tiempos de pandemia. Evidentemente existen personas que no son receptivas a estos mensajes policiales, o que simplemente actúan de manera egoísta (e ignorante) y que han de ser forzadas al cumplimiento de la normativa en estos casos, ya que, en la medida en qué su actuación puede afectar a terceras personas, no se puede defender su libertad individual a someterse a los riesgos sanitarios que implica la pandemia. Evidentemente la Policía ha de tener esto en cuenta y actuar para evitar estos comportamientos asociales, sobre todo cuando sean altamente peligrosos o sean muy recalcitrantes.

En todo caso, hay que tener en cuenta que la normativa en tiempo de pandemia es muy compleja, cambia constantemente en función de la situación sanitaria, siendo difícil incluso para la policía estar al día (Hough, M., 2021), y frecuentemente hay normas que son difícilmente comprensibles para la población (por ejemplo, la prohibición establecida en España las primeras seis semanas de pandemia de que los convivientes de una misma unidad de convivencia circularan juntos por la vía pública). Es por ello que una aplicación ponderada, priorizando la información y el consejo y dejando sólo para casos de resistencia clara y directa la denuncia y otras medidas coercitivas parecen recomendables. Principalmente, teniendo en cuenta que hay sectores muy vulnerables que tienen más dificultades para cumplir con los mandatos legales en tiempos de pandemia, que pueden ver empeorada su situación si se les produce una aplicación estricta y directa y que ello puede afectar a la confianza entre ellos y la Policía, dificultando la eficacia de esta última en el futuro.

El pánico de la población, la necesidad de los gobernantes de demostrar capacidad reactiva, no pueden centrarse en la actuación de la policía para ocultar deficiencias estructurales en el ámbito de la sanidad o de la justicia social. Ello no hará sino debilitar la posición de la Policía ante la ciudadanía, dificultará la colaboración futura entre ellos y favorecerá la inseguridad y la delincuencia (especialmente la organizada, en casos como México o Italia dónde ésta ha intentado ganarse a sectores de la población con ayudas que el Estado no ofrecía).

\section{TRABAJOS CITADOS}

Aston, L. (2020) "Covid-19 Implications for Policing". In Our Blog: The Justice Stories. The Scottish Centre for Crime \& Justice Research. 30 abril. (https://sccjrblog.wordpress. com/2020/04/30/covid-19-implications-for-policing/ ).

Aston, L., Brandariz, J.A., Czerwinska, D., De Kimpe, S., de Maillard,J., Hoffman, I., O’Neil, M, Rowe,M, y Solhjell, R. (2020) "White paper: Policing the pandemic". https:// polstops.eu/wp-content/uploads/2020/10/White-PaperPolicing-the-Pandemic.pdf

Barrón, M.G. (2015). Gobernar con el miedo. La lucha contra el narcotráfico (2006-2012). Ciudad de México. Ed. Novum, Inacippe.

Brooks, R.; López, C. (2020). "Policing in a Time of Pandemic: Recommendations for Law Enforcement". En COVID-19 Rapid Response Impact Initiative | White Paper 7. Edmond 
J. Safra Centee for Ethics. Washington. ( https://ethics. harvard.edu/files/center-for-ethics/files/7policingpandemic. pdf?m=1590500595 )

Campedelli, G.M., y D'Orsogna, M.R. (2021). "Temporal clustering of disorder events during the Covid-19 pandemic". arXiv:2101.06458 [physics.soc-ph] ( https:// arxiv.org/abs/2101.06458).

Carbonaro, G., y Somara, S. (2020). Policing tactics "key" to minimizing COVID-19 protests risk. ( https://newseu.cgtn. com/news/2020-06-16/Policing-tactics-key-to-minimizingCOVID-19-protests-risks-RIDwpWVrYk/index.html )

Felson, M., Cohen, L.E. (1980) "Human ecology and crime: A routine activity approach". Hum Ecol 8: Pp. 389-406 (1980). https://doi.org/10.1007/BF01561001

Flores, C.A. (2009). El Estado en crisis: crimen organizado y política. Desafíos para la consolidación democrática. México. CIESAS.

Greene, A. (2020). Emergency powers in a time of pandemic. Bristol University Press.

Grace, S. (2020). "Policing social Distancing: gaining and Mantaining Compliance in the Age of Coronavirus". En Policing. Vol,0, num. 0. Pp.1-20.

Grup de Treball de Violències Masclistes del Consell Nacional de la Dona de Catalunya (CNDC) (2020). En la crisi del covid-19 visibilitzem la precarietat amb perspectiva de gènere https://dones.gencat.cat/web/.content/02_ institut/12-cndc/Altres_doc/PRECARIETAT-CNDC.pdf

Guillén, F. (2015). Modelos de policía y seguridad. Tesis doctoral. Universidad Autónoma de Barcelona. ( https:// ddd.uab.cat/record/132354).

Guillén, F. (2016). Modelos de policía. Hacia un modelo de seguridad plural. Barcelona. Bosch editor.

Guillén, F. (2018). Desencuentros entre la Policía y el Público. Barcelona. Bosch editor.

Guillén, F. (2020a). "La falacia de la seguridad objetiva y sus consecuencias". International E-Journal of Criminal Sciences. Núm, 15. ( https://ojs.ehu.eus/index.php/inecs/ article/view/21484 )
Guillén, F. (2020b). "Policing during Covid-19: An Unprecedented Emergency". En Vaccine, a CCI Newsletter. Núm. 3. ( https://zc1.campaign-view.eu/ua/ ) y https://bit. ly/3Ad8kSx

Her Majesty Inspectorate of Constabulary and Fire \& Rescue Services (HMICFRS) (2021). Policing the Pandemic. The police response to the coronavirus pandemic in 2020.

Hough, M. (2021). Good Policing. Trust, legitimacy and authority. Bristol. Bristol University Press.

Interpol (2020). Pandemia de Covid19. Protección de la Policía y la Población. Directrices para las fuerzas del orden. Primera edición de marzo, segunda edición de noviembre. Jennings, W.G.; Pérez, N.M. (2020). "The immediate Impact of COVID-19 on Law Enforcement in the United Sates". En American Journal of Criminal Justice. 45. PP.690-701. (https://doi.org/10.1007/s12103-020-09536-2 ).

Laufs'J., y Waseem, Z. (2020). "Policing in pandemics: A systematic review and best practices for police response to COVID-19". En Int J Disaster Risk Reduct. 2020 Dec; 51: 101812. Published online 2020 Aug 20. doi: 10.1016/j. ijdrr.2020.101812 (https://www.ncbi.nlm.nih.gov/pmc/ articles/PMC7439012/)

NENA. The 9-1-1 Association (2020). 9-1-1 \& COVID19.A Report on PSAPs During the Pandemic https:// portal.educoas.org/sites/default/files/nw/docs/NENA_ COVID-19_Impact_PSAPs.pdf

Roché, S. (2020). "Le Coronavirus, I'exception et la culture politique des élites ». En Esprit. Mayo. ( https://esprit.presse. fr/actualites/sebastian-roche/le-coronavirus-l-exception-etla-culture-politique-des-elites-42766 )

Sheptycki, J. (2020). "The politics of policing a pandemic panic". En Australian \& New Zealand Journal of Criminology. Vol. 53(2). Pp. 157-173.

Tyler, T.R. (1996). Why people obey the law. Princeton University Press.

Tyler, T.R. (2003). "Procedural Justice, Legitimacy, and the Effective Rule of Law". En Crime and Justice. Vol. 30. Pp 283-357.

Tyler, T.R. (2011). "Trust and legitimacy: Policing in the USA 
and Europe". En European Journal of Criminology. Vol. 8(4):

Pp. 254-266.

Valdivia, J.A.; Hernández, G.D., y Maiz, S.I. (2021)."Burnout in Police Officers from Northern Mexico: a Validity Study of the Maslach Burnout Inventory." En Journal of Police and Criminal Pschology.

Wells, H., Aston, L., O’Neil, M., y Bradford, B., (2020). "The rise of technologically-mediated police contact: the potential consequences of "socially-distanced policing"". En BSC Policing Network. (https://bscpolicingnetwork. com/2020/04/29/the-rise-of-technologically-mediatedpolice-contact-the-potential-consequences-of-sociallydistanced-policing/)

\section{Fransesc Guillen Lasierra}

Afiliación: Universidad Autónoma de Barcelona, España.

Doctor en Criminología Miembro del Departamento del interior de Generalitat de Cataluña y profesor investigador de la Universidad Autónoma de Barcelona. 